Article

\title{
Comparison of SEVIRI-Derived Cloud Occurrence Frequency and Cloud-Top Height with A-Train Data
}

\author{
Chu-Yong Chung ${ }^{1, *}$, Peter N. Francis ${ }^{2}$, Roger W. Saunders ${ }^{2}$ and Jhoon Kim ${ }^{3}$ \\ 1 National Meteorological Satellite Center, Korea Meteorological Administration, 64-18 Guam-gil, \\ Gwanghyewon-myeon, Jincheon-gun, Chuncheonbuk-do 27803, Korea \\ 2 Met Office, FitzRoy road, Exeter, Devon EX1 3PB, UK; pete.francis@metoffice.gov.uk (P.N.F.); \\ roger.saunders@metoffice.gov.uk (R.W.S.) \\ 3 Department of Atmosphere Sciences, Yonsei University, 50 Yonsei-ro, Seodaemun-gu, Seoul 03722, Korea; \\ jkim2@yonsei.ac.kr \\ * Correspondence: cychung@kma.go.kr; Tel.: +82-70-7850-5903
}

Academic Editors: Alexander A. Kokhanovsky, Richard Müller and Prasad S. Thenkabail Received: 7 October 2016; Accepted: 22 December 2016; Published: 30 December 2016

\begin{abstract}
To investigate the characteristics of Spinning Enhanced Visible and Infrared Imager (SEVIRI)-derived products from the UK Met Office algorithm, one year of cloud occurrence frequency (COF) and cloud-top height (CTH) data from May 2013 to April 2014 was analysed in comparison with Cloud Profiling Radar (CPR) and Cloud-Aerosol LiDAR with Orthogonal Polarization (CALIOP) cloud products observed from the A-Train constellation. Because CPR operated in daylight-only data collection mode, daytime products were validated in this study. It is important to note that the different sensor characteristics cause differences in CTH retrievals. The CTH of active instruments, CPR and CALIOP, is derived from the return time of the backscattered radar or LiDAR signal, while the infrared sensor, SEVIRI, measures a radiatively effective CTH. Therefore, some systematic differences in comparison results are expected. However, similarities in spatial distribution and seasonal variability of COFs were noted among SEVIRI, CALIOP, and CPR products, although COF derived by the SEVIRI algorithm showed biases of $14.35 \%$ and $-3.90 \%$ compared with those from CPR and CALIOP measurements, respectively. We found that the SEVIRI algorithm estimated larger COF values than the CPR product, especially over oceans, whereas smaller COF was detected by SEVIRI measurements over land and in the tropics than by CALIOP, where multi-layer clouds and thin cirrus clouds are dominant. CTHs derived from SEVIRI showed better agreement with CPR than with CALIOP. Further comparison with CPR showed that SEVIRI CTH was highly sensitive to the $\mathrm{CO}_{2}$ bias correction used in the Minimum Residual method. Compared with CPR CTHs, SEVIRI has produced stable CTHs since the bias correction update in November 2013, with a correlation coefficient of 0.93 , bias of $-0.27 \mathrm{~km}$, and standard deviation of $1.61 \mathrm{~km}$.
\end{abstract}

Keywords: SEVIRI; cloud-top height; validation; CPR; CALIOP; bias correction

\section{Introduction}

Current uncertainties in the roles played by clouds and aerosols in the Earth's radiation budget limit our understanding of the climate system and the potential for global climate change [1], as well as weather analysis and forecasting. Clouds are highly variable in space and time, and they influence both solar and thermal radiative transfer in addition to the water cycle. Optically thick, low-level clouds usually have a negative net radiative forcing because their thermal effect is small, although the reflection of the solar radiance dominates. In contrast, the net radiative effect of high-level clouds is often positive because the thermal contrast between them and the surface is large [2,3]. Thus, detailed monitoring of cloud properties is required to understand the distribution and impact of clouds on 
regional and global scales. Satellites can provide information on the global distribution of cloud cover and cloud properties and variations. Measurements from passive satellite imagers at visible to thermal infrared wavelengths on board many geostationary and polar orbiting satellites provide a wealth of information on cloud properties. The current operational geostationary satellite in Europe, Meteosat Second Generation (MSG) has the 12-channel Spinning Enhanced Visible and Infrared Imager (SEVIRI) and provides high temporal frequency observations every $15 \mathrm{~min}$ to help deliver information on cloud characteristics.

The UK Met Office uses data from Meteosat satellites for weather analysis and forecasting. Cloud parameters are derived operationally from radiances observed by SEVIRI and include cloud detection, cloud-top temperature, height, and effective cloud amount (ECA), which is the product of the fractional coverage and the cloud emissivity. These parameters are used as image interpretation tools for forecasters and as inputs to numerical weather prediction (NWP) and automated nowcasting systems [4]. Validation of these satellite-derived cloud parameters is important for understanding their accuracies and characteristics for use in various applications. Many validation studies have been conducted with ground-based reference data, such as observations from cloud radar [5], Cloudnet [6], and aircraft experiments [7]. However, these validations are obviously restricted in space and time. Moreover, inter-satellite comparisons of cloud parameters are more resistant to the deficiencies in temporal and spatial coverage and have thus been effective in determining the value and limitations of various satellite products. The Cloud Retrieval Evaluation Workshop (CREW) has led research activities in evaluating the strengths and weaknesses of the well-established algorithms that retrieve cloud properties from passive imager instruments such as SEVIRI, Advanced Very-High-Resolution radiometer (AVHRR), and Moderate Resolution Imaging Spectroradiometer (MODIS) on board both polar and geostationary satellites. CREW working group members operate the highly-advanced cloud retrieval algorithms. The UK Met Office has participated in CREW and has provided cloud products including the CREW Common Database for five "golden" days, which have been inter-compared and validated against observations from the A-Train satellite constellation by Cloud-Aerosol LiDAR and Infrared Pathfinder Satellite Observations (CALIPSO), CloudSat, and Aqua. The A-Train Validation of Aerosol and Cloud Properties from SEVIRI (AVAC-S) software [8] was developed in the European Organisation for the Exploitation of Meteorological Satellites (EUMETSAT) to support this activity.

In this study, AVAC-S software was developed and used for validating the UK Met Office cloud products for one year of data. This study is organized as follows. Section 2 briefly introduces the cloud data from SEVIRI, Cloud Profiling Radar (CPR), and Cloud-Aerosol LiDAR with Orthogonal Polarization (CALIOP), which are used in this comparison study. In addition, the AVAC-S system and the methodology used to validate cloud products are presented. In Section 3, some details of SEVIRI cloud cover and cloud-top height $(\mathrm{CTH})$ validation results are compared with CPR and CALIOP products. We discuss the results and compare them with those of previous studies in Section 4 . Section 5 summarises and concludes the study.

\section{Materials and Methods}

\subsection{Datasets}

The UK Met Office has utilised Meteosat data in real time to retrieve products for various applications. Meteosat-10 data have been operational since 21 January 2013 after its launch on 5 July 2012. The SEVIRI instrument on the MSG satellites has a set of channels designed to provide accurate cloud-top properties [9].

The first step in deriving SEVIRI cloud parameters is to produce a cloud mask that identifies clear, partly cloudy and fully cloudy fields of view using the techniques previously developed for AVHRR [10]. However, an important development for processing MSG radiances is the inclusion of clear sky simulated radiances calculated using the Unified Model (UM) profiles input into the Radiative Transfer for Television Infrared Observation Satellite Operational Vertical Sounder (RTTOV), 
which is a fast radiative transfer model [11]. This allows for an excellent opportunity for comparing the differences between observed and simulated radiances, which should be small for clear sky scenes. The cloud detection tests encompass spectral differencing by using various channel combinations and comparing the measured and simulated differences. Spatial coherence and visible reflectance information is also used. Additionally, for low cloud detection in twilight conditions, the temporal differencing technique is applied in accordance with the frequent observation merit of geostationary satellites [12].

The UK Met Office SEVIRI-derived cloud-top products contain information about the cloud-top pressure (CTP), temperature (CTT), and height (CTH) relative to the local topography for pixels identified as cloudy in the satellite scene. These cloud-top products were derived by using three independent algorithms in the following order: Minimum Residual (MR), Stable Layers (SL), and Profile Matching (PM) methods. First, the identified cloudy pixels are assigned to a cloud-top pressure and ECA by using an MR technique [13] based on an NWP forecast profile and SEVIRI radiances. Currently, three SEVIRI channels, including two infrared windows at 10.8 and $12.0 \mu \mathrm{m}$, and a $\mathrm{CO}_{2}$ absorption channel at $13.4 \mu \mathrm{m}$, are used in this technique. The atmospheric stability from the background NWP model profile is also considered to ensure that the cloud is not placed at the bottom of an unstable layer. The CTP from the MR method is used mainly for the assignment of high clouds, of which CTP is less than $480 \mathrm{hPa}$. An SL method is employed if a suitable solution is not found by the MR method, that is, if the uncertainty in the MR solution is greater than a prescribed threshold, which is normally the case for low cloud. The SL method uses the $10.8 \mu \mathrm{m}$ window channel radiance and attempts to find the best level for the cloud-top to obtain an agreement between observed and simulated radiances. The concept of this method is based on the knowledge that clouds are normally topped by a stable layer that prevents the air parcels from rising further [14,15]. In practice, this means that the upper-level clouds tend to use the solution of the MR method, and the lower-level clouds apply the SL method with a priori constraints. If no proper CTP solution is obtained from these two methods, the PM method, which has no a priori constraint, is used as a fallback solution; however, such cases are rare. This approach begins at the bottom of the profile and moves the cloud layer upward until agreement with the observed radiance at $10.8 \mu \mathrm{m}$ is achieved. After the ECA and CTP are determined, CTT and CTH are obtained through the conversion of the UM background vertical profile.

\subsubsection{CPR/CloudSat}

CloudSat is a satellite experiment designed to measure the vertical structure of clouds and to observe cloud and precipitation from space simultaneously with A-Train satellite constellation [16]. The primary CloudSat instrument is a $94 \mathrm{GHz}$, near nadir-looking, CPR which measures the power backscattered by clouds. CloudSat was launched in tandem with CALIPSO, a second Earth System Science Program (ESSP) mission, which is equipped with CALIOP, a dual frequency LiDAR instrument. The CPR was developed jointly by the National Aeronautics and Space Administration (NASA)/Jet Propulsion Laboratory (JPL) and the Canadian Space Agency (CSA). The overall design of the CPR has a strong heritage from many cloud radars presently in operation in ground-based and airborne applications. The CPR samples profiles at $625 \mathrm{kHz}$, correspond to a range of sampling distance of $240 \mathrm{~m}$. Each profile has 125 vertical bins. One vertical profile of the atmosphere is recorded every $0.16 \mathrm{~s}$ by averaging approximately 600 pulses. CPR provides an instantaneous footprint of approximately $1.3 \mathrm{~km}$ across-track by $1.7 \mathrm{~km}$ along-track at mean sea level [17]. The Cooperative Institute for Research in the Atmosphere (CIRA) CloudSat Data Processing Center (DPC) generates and provides the data for subsequent level 0 (raw data) through level 2 (derived products), including radar backscatter profiles (1B-CPR), cloud geometrical profiles (2B-GEOPROF), cloud classification (2B-CLDCLASS) and other products. The data used in this study are radar backscattering profiles and CTH in 2B-GEOPROF acquired from CIRA CloudSat DPC (ftp://ftp1.cloudsat.cira.colostate.edu). CTH data were obtained from height values for 125 vertical bins and the cloud mask, indicating the presence of a cloud inside a CPR bin. The cloud mask has values of 0 for clear condition, 1 for error, 5 for ground clutter, 
5-10 when the bin is judged to be contaminated by clouds weakly through the along-track integration, and 20-40 when clouds are detected. A larger cloud mask value is related to a higher confidence in cloud detection. CloudSat project team suggested that vertically connected CloudSat bins with significant cloud mask values $(\geq 30)$ are regarded as a cloud layer [18]. Marchand et al. [19] analysed the sensitivity of CPR cloud detection to different CPR cloud mask values compared with CALIOP observations. In this study, CPR CTH is defined as a layer at the point where the accumulated value from the top downward becomes larger than 30 as defined by the AVAC-S software.

\subsubsection{CALIOP/CALIPSO}

CALIPSO is a joint NASA-Centre National D'études Spatiales (CNES) satellite mission designed to provide measurements aimed at improving our understanding of the role of aerosols and clouds in the climate system. The CALIPSO satellite was launched in April 2006 together with the CloudSat satellite. CALIPSO and CloudSat fly in close formation as part of the A-Train satellite constellation. The satellite carries CALIOP as a primary instrument, which provides detailed profile information of cloud and aerosol particles and their corresponding physical parameters. CALIOP measures high-resolution profiles $(1 / 3 \mathrm{~km}$ in the horizontal and $30 \mathrm{~m}$ in the vertical at $532 \mathrm{~nm}$ in low and middle troposphere) of the attenuated backscatter by aerosols and clouds at visible (532 nm) and near-infrared $(1064 \mathrm{~nm})$ wavelengths along with polarized backscatter in the visible channel [20]. Accurate aerosol/cloud heights and extinction coefficient profiles are derived from the total backscatter measurements. The depolarization measurements enable the discrimination between ice clouds and water clouds and the identification of non-spherical aerosol particles. Additional information, such as the estimates of aerosol particle size, is obtained from the ratios of the signals obtained at the two wavelengths.

CALIOP provides information for layers down to the level in which the LiDAR signal is fully attenuated even in the case of multi-layer clouds, which occurs at the cumulative optical depth of 3-5. However, the interpretation of CALIOP measurements is often limited by a low signal to noise ratio when using the original high-resolution profiles. Therefore, measurements are usually averaged over several LiDAR shots to allow for a higher confidence in the correct detection and identification of cloud layers. CALIOP products are retrieved from the NASA Langley Atmospheric Science Data Center (ASDC: Hampton, VA, USA; http:/ / eosweb.larc.nasa.gov) and defined in three different versions with respect to the along-track resolution: $333 \mathrm{~m}$ (individual FOVs), $1 \mathrm{~km}$, and $5 \mathrm{~km}$. In this study, LiDAR Level-2 5-km Cloud Layer information (Version 3) was used considering the confidence in addition to the corresponding SEVIRI product resolution, which is $3 \mathrm{~km}$ at the nadir and becomes larger towards higher latitude regions. The highest level CTHs were used in this comparison study, although CALIOP provided the cloud layer top altitudes in the case of multi-layer clouds.

\subsection{Methodology}

The main tool used in this study is AVAC-S software developed by EUMETSAT, which is related to CREW activity [8]. Optimal Cloud Analysis (OCA), Cloud Analysis (CLA) from EUMETSAT, and Climate Monitoring Satellite Application Facility (CMSAF) cloud products are included within the validation targets of AVAC-S. This information is intended to support scientists in evaluating processing schemes used to derive physical parameters from MSG-SEVIRI measurements in comparison with the relevant parameters from polar orbiting A-Train sensors, which offer high-accuracy, independent information. The main function of AVAC-S is the mapping of MSG-SEVIRI data and A-Train data, including CPR, CALIOP, MODIS, and Polarization and Directionality of the Earth's Reflectances (POLDER) products, on a common grid with several utilities for analysis and visualisation. AVAC-S software was set up in the UK Met Office; the ingestion routine for the SEVIRI parameters was added for this study. 


\subsubsection{Data Period}

One year's worth of data, from May 2013 to April 2014, was used in this comparison study. Because the amount of data is large, we collected data every seven days during that period and created a matchup dataset including a total of 329 CPR overpasses. Because the CPR instrument has been in daylight-only data collection mode since October 2011 after undergoing a battery anomaly problem [21], only the daytime observations are used in this comparison study.

\subsubsection{Matching SEVIRI and A-Train Observations}

The A-Train satellites regularly overfly the SEVIRI/MSG observation disk. AVAC-S generates the matchup data of the SEVIRI and A-Train products on the basis of the CPR overpass, which is assumed to be the best-suited instrument for validating SEVIRI cloud parameters. The matching method we used in this study is the same as the one Hamann et al. [3] used. However, we did not use parallax correction function in AVAC-S for the SEVIRI viewing zenith angle as in Hamann et al. [3]; instead we used parallax-corrected $\mathrm{CTH}$ products when generating matchup datasets.

\subsubsection{Validation Methods and Scores}

The statistical validation scores are calculated using the daily and monthly datasets merged from each individual matchup pixel along the matchup track. In the case of cloud occurrence frequency (COF), the SEVIRI parallax-corrected CTH product is used. If CTH data on the corresponding pixel exists, it is assumed to be cloudy, and vice versa. A cloudy pixel from cloud detection can be considered a clear pixel when the simulated radiance does not sufficiently converge to the observed radiance in the CTH retrieval process and also when the error from a different satellite viewing angle is reduced. The CTH are not retrieved over the partly cloudy pixel, thus the partly cloudy pixels are not dealt with in the COF analysis. A binary representation of the results, where cloud cover values of 1 and 0 for cloudy and clear conditions, respectively, are used for each individual pixel. The results are accumulated over the full matchup tracks for each individual month to obtain the scores for COF. It should be noted that the scores are computed by using the matchup data that contain valid CTH values in all three products, CPR, CALIOP, and SEVIRI. For validation with CPR or CALIOP, the mean $\mathrm{COF}$ and bias can be computed as

$$
\begin{gathered}
\text { MeanCOF }=\frac{\sum \text { cloudy }}{\text { Eallpixels }} \\
\text { bias }=\text { MeanCOF }_{\text {SEVIRI }}-\text { MeanCOF }_{r e f}
\end{gathered}
$$

For the other scores, we used the following definitions referring to the notations in the contingency matrix in Table 1 [22].

Table 1. Contingency matrix for comparison of Spinning Enhanced Visible and Infrared Imager (SEVIRI) cloud occurrence frequency (COF) with the cloud products from A-Train.

\begin{tabular}{ccc}
\hline & SEVIRI Cloudy & SEVIRI Clear \\
\hline $\begin{array}{c}\text { Reference cloudy (CPR or CALIOP) } \\
\text { Reference clear (CPR or CALIOP) }\end{array}$ & c: false positives & d: correct negatives \\
\hline
\end{tabular}

Note: CPR: Cloud Profiling Radar; CALIOP: Cloud-Aerosol LiDAR with Orthogonal Polarization.

Probability of detection (POD) for both cloudy and cloud-free conditions:

$$
\mathrm{POD}_{\text {cloudy }}=\frac{a}{a+b}
$$




$$
\mathrm{POD}_{\text {clear }}=\frac{d}{c+d}
$$

False alarm ratio (FAR) for both cloudy and cloud-free conditions:

$$
\begin{aligned}
& \mathrm{FAR}_{\text {cloudy }}=\frac{c}{a+c} \\
& \text { FAR }_{\text {clear }}=\frac{b}{b+d}
\end{aligned}
$$

Proportion correct (PC):

$$
\mathrm{PC}=\frac{a+d}{a+b+c+d}
$$

Hanssen-Kuiper's skill score (KSS) or True Skill Statistic (TSS):

$$
\mathrm{KSS}=\frac{a \cdot d-b \cdot c}{(a+b) \cdot(c+d)}
$$

The POD and FAR scores estimate the SEVIRI efficiency in determining cloudy or clear conditions. POD (FAR) values are desired to be as high (low) as possible. The PC, which is also known as the accuracy or hit rate, is a condensed measure of the overall efficiency of cloud detection. Finally, the KSS quantity is a counter measure because the PC is heavily influenced by the results for the most common category and can sometimes be misleading. For example, if a case is almost totally cloud-free and all of the few cloudy portions are missed by SEVIRI, the PC score will still be high. The KSS score is more robust: 1 very good; -1 very bad. For cloud detection schemes, values above 0.5 show that the scheme is reliable and skilled. Along with quantitative analysis using the statistical scores, qualitative analysis was also conducted to evaluate the cloud detection performance of SEVIRI. The COF distribution in the SEVIRI observation area was analysed, and its seasonal variation and detection tendency over land and ocean was investigated.

SEVIRI CTHs were compared with the corresponding measured maximum cloud-top values as interpreted from CPR and CALIOP vertical cloud classification. In the case of CTH, we restricted the number of validation scores to just two, including bias (mean error) and standard deviation (bias-corrected root-mean-square differences).

CTH bias:

$$
\begin{gathered}
\Delta \mathrm{CTH}=\mathrm{CTH}_{\text {SEVIRI }}-\mathrm{CTH}_{r e f} \\
\text { bias }=\frac{1}{N} \sum^{N-1} \Delta \mathrm{CTH} .
\end{gathered}
$$

Standard deviation:

$$
\mathrm{SD}=\sqrt{\frac{1}{N-1} \sum^{N-1}[\Delta \mathrm{CTH}-\overline{\Delta \mathrm{CTH}}]^{2}}
$$

Owing to different characteristics of satellite observations, such as differences in viewing geometry and observation time, unwanted large CTH differences can be found, particularly over non-homogenous cloud areas. Thus, two filters were used in this study for evaluating and characterising the SEVIRI CTH products more strictly. The first is a spatial uniformity filter, which excludes the data when the CTH standard deviation of the surrounding $5 \times 5$ pixels is larger than $1 \mathrm{~km}$. The second is that any data with large CTH variances from the SEVIRI output $\left(\geq 1 \mathrm{~km}^{2}\right)$ are filtered out because they do not converge sufficiently for generating accurate $\mathrm{CTH}$ values in the cloud retrieval algorithm. 


\section{Results}

\subsection{Cloud Occurrence Frequency}

Table 2 summarises all of the matchup results for individual months for the mean COFs for CPR, CALIOP, and SEVIRI cloud products; bias scores of SEVIRI against CPR and CALIOP products; and the numbers of co-located data used to calculate the validation scores. It should be noted that the numbers of co-located data in January and February 2014 were relatively small owing to the outage of Meteosat-10 for scheduled decontamination on 14-21 January 2014, in addition to a data collection failure for this study during that period. Most of the matchup data were collected from the SEVIRI observation area with a higher satellite zenith angle because of the collocation time calculation fault; thus, the scores do not have strong consistency and should be interpreted carefully. The bias score clearly shows that CALIOP estimated a greater COF of $61.23 \%$ for the comparison period from May 2013 to April 2014. In addition, CPR detected a significantly lower COF of $42.98 \%$, and SEVIRI COF was in the middle but was closer to that of CALIOP with a value of $57.33 \%$. That is, CALIOP showed a COF 3.90\% higher (in absolute terms) than that derived for SEVIRI, whereas CPR showed a COF $14.35 \%$ lower than that for SEVIRI. On the seasonal variation of monthly-mean COFs, a trend is apparent in all three products such that COFs increased in the boreal winter and early spring and decreased in the boreal summer over the Meteosat-10 observation area, where December-February (June-August) represents boreal winter (summer). The monthly-mean COFs of CPR, CALIOP, and SEVIRI varied within 9\% from 37.01 to 46.04 , 13\% from 53.20 to 66.19 , and 9\% from 51.39 to 60.51 , respectively, when ignoring January and February due to the statistical insignificance. CALIOP showed slightly larger seasonal variability. The bias of the SEVIRI COF was from 13.09 to 15.89 compared with the CPR and from -5.68 to -1.57 for CALIOP.

Table 2. Summary of cloud occurrence frequencies over all matchup cases per month among Cloud Profiling Radar (CPR), Cloud-Aerosol LiDAR with Orthogonal Polarization (CALIOP), and Spinning Enhanced Visible and Infrared Imager (SEVIRI). All results are given in cloud occurrence frequency units (\%).

\begin{tabular}{|c|c|c|c|c|c|c|c|}
\hline \multirow{2}{*}{ Year } & \multirow{2}{*}{ Month } & \multicolumn{3}{|c|}{ Mean Cloud Occurrence (\%) } & \multicolumn{2}{|c|}{ SEVIRI Bias (\%) } & \multirow{2}{*}{ Number of Data } \\
\hline & & CPR & CALIOP & SEVIRI & CPR & CALIOP & \\
\hline \multirow{8}{*}{2013} & May & 43.39 & 61.70 & 57.32 & 13.93 & -4.38 & 68162 \\
\hline & June & 38.85 & 57.31 & 53.25 & 14.40 & -4.06 & 59384 \\
\hline & July & 37.01 & 53.20 & 51.39 & 14.38 & -1.81 & 77620 \\
\hline & August & 40.67 & 58.13 & 56.56 & 15.89 & -1.57 & 82891 \\
\hline & September & 40.69 & 58.76 & 55.68 & 14.99 & -3.08 & 72390 \\
\hline & October & 42.16 & 61.85 & 57.36 & 15.20 & -4.49 & 67751 \\
\hline & November & 44.14 & 61.93 & 58.46 & 14.32 & -3.47 & 82263 \\
\hline & December & 45.12 & 66.19 & 60.51 & 15.39 & -5.68 & 97163 \\
\hline \multirow{4}{*}{2014} & January & 55.40 & 64.16 & 64.01 & 8.61 & -0.15 & 8466 \\
\hline & February & 52.64 & 66.95 & 57.56 & 4.92 & -9.39 & 11934 \\
\hline & March & 45.94 & 64.35 & 60.21 & 14.27 & -4.14 & 80800 \\
\hline & April & 46.04 & 64.36 & 59.13 & 13.09 & -5.23 & 107137 \\
\hline \multicolumn{2}{|c|}{ Overall mean } & 42.98 & 61.23 & 57.33 & 14.35 & -3.90 & 815961 \\
\hline
\end{tabular}

To investigate the COF tendency with regard to the surface type, we computed the scores over land and ocean separately (Table 3). About $64 \%$ of the derived matchup dataset corresponded to ocean pixels, with the remainder over land surfaces. All COFs showed larger values over the ocean. The differences of COFs with respect to the surface type were about $7 \%-11 \%$ for the CPR and the CALIOP products, increasing to about $20 \%$ for SEVIRI. The SEVIRI product even showed a positive bias over the ocean compared with CALIOP in the monthly statistics for most months except for 
December and April (not shown here). This means that the SEVIRI algorithm detected clouds very rigorously over the ocean surface.

Table 3. Mean cloud occurrence frequencies and the biases of Spinning Enhanced Visible and Infrared Imager (SEVIRI) cloud products with regard to the surface type (land/ocean) for a one-year validation period.

\begin{tabular}{ccccccc}
\hline \multirow{2}{*}{ Surface Type } & \multicolumn{3}{c}{ Mean Cloud Coverage (\%) } & \multicolumn{2}{c}{ SEVIRI Bias (\%) } & \multirow{2}{*}{ Number of Data } \\
\cline { 2 - 5 } & CPR & CALIOP & SEVIRI & CPR & CALIOP & \\
\hline All & 42.98 & 61.23 & 57.33 & 14.35 & -3.90 & 815961 \\
Land & 35.67 & 56.87 & 44.74 & 9.07 & -12.14 & 291108 \\
Ocean & 47.03 & 63.65 & 64.32 & 17.28 & 0.67 & 524853 \\
\hline
\end{tabular}

Note: CPR: Cloud Profiling Radar; CALIOP: Cloud-Aerosol LiDAR with Orthogonal Polarization.

Table 4 provides POD, FAR, PC, and KSS scores derived from the matchup dataset, for the different surface types. In comparison between SEVIRI and CPR, POD cloudy was high with values close to 0.90 and large $\mathrm{FAR}_{\text {cloudy }}$ values around 0.32. In addition, both $\mathrm{POD}_{\text {clear }}$ and FAR $\mathrm{R}_{\text {clear }}$ were low, with values of 0.67 and less than 0.1 , respectively. Poor $P O D_{\text {clear }}$ and $F A R_{\text {cloudy values were expected }}$ because SEVIRI detected more clouds than CPR with a COF bias of $14.35 \%$. Over land, POD cloudy

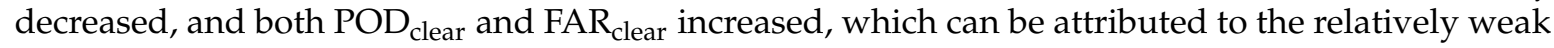
cloud detectability of SEVIRI over land. Moreover, for the comparison with CALIOP, POD cloudy $_{\text {and }}$ $\mathrm{FAR}_{\text {clear }}$ showed less accurate results of 0.82 and 0.25 , respectively, than those of the CPR case. However,

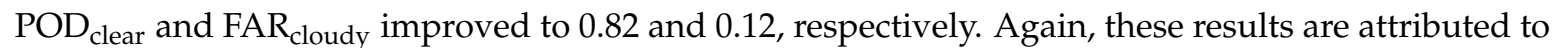
the high sensitivity of CALIOP to clouds. According to PC, KSS, and the scores previously described, the SEVIRI COF showed closer agreement with the CALIOP COF than the CPR COF. However, the SEVIRI COF appears to have a relative weakness in detecting clouds over land in general.

Table 4. Probability of detection (POD), false alarm ratio (FAR), proportion correct (PC), and Kuiper's skill score (KSS) scores of Spinning Enhanced Visible and Infrared Imager (SEVIRI) cloud detection compared with Cloud Profiling Radar (CPR) and Cloud-Aerosol LiDAR with Orthogonal Polarization (CALIOP) with regard to surface type.

\begin{tabular}{ccccccccc}
\hline Reference Data & Surface Type & POD $_{\text {cloudy }}$ & POD $_{\text {clear }}$ & FAR $_{\text {cloudy }}$ & FAR $_{\text {clear }}$ & PC & KSS & Number of Data \\
\hline \multirow{3}{*}{ CPR } & All & 0.9019 & 0.6743 & 0.3239 & 0.0988 & 0.7722 & 0.5763 & 815961 \\
& Land & 0.8340 & 0.7669 & 0.3351 & 0.1072 & 0.7909 & 0.6009 & 291108 \\
& Ocean & 0.9305 & 0.6120 & 0.3196 & 0.0916 & 0.7618 & 0.5425 & 524853 \\
\hline \multirow{3}{*}{ CALIOP } & All & 0.8231 & 0.8213 & 0.1209 & 0.2538 & 0.8224 & 0.6444 & 815961 \\
& Land & 0.7147 & 0.9051 & 0.0914 & 0.2936 & 0.7968 & 0.6199 & 291108 \\
& Ocean & 0.8769 & 0.7661 & 0.1322 & 0.2196 & 0.8366 & 0.6430 \\
\hline
\end{tabular}

In order to infer the spatial distribution of the mean COFs, the matchup data were grouped into latitude-longitude grid boxes of $2^{\circ} \times 2^{\circ}$. The estimated mean COF distributions and the differences are presented in Figure 1. The grey-scale brightness in the upper panel of the Figure 1 presents the mean COF maps over the grid box for CPR, CALIOP, and SEVIRI. The values range from 0 (dark) to 1 (white); the boxes with white " $x$ " symbols with a black background in the figure show that no data were collected in those areas. The coloured maps in the lower panel show the differences in the mean COF among SEVIRI, CPR, and CALIOP. The red (blue) colour indicates that the SEVIRI mean COF is larger (smaller). A high frequency of clouds occurred most often in the inter-tropical convergence zone (ITCZ) and mid-latitude storm belts along with lower concentrations occurred in subtropical deserts and oceanic subtropical highs. The COF distribution patterns for the CPR, CALIOP, and SEVIRI products showed generally good agreement. However, CPR (CALIOP) had the lowest (highest) frequencies over most areas. These trends were more distinct over the broad region near the ITCZ. Again, the SEVIRI COFs were generally between those of CPR and CALIOP. It is clear 
that the CPR COFs were distributed less with much lower frequency than those of SEVIRI except for the desert areas that are nearly cloudless over the year, such as Sahara and Kalahari in Africa, and Syria and Arabia in the Middle East. In contrast with the CPR data, the CALIOP estimation of COFs was significantly higher and showed relatively high frequency. This trend was particularly apparent over the tropical convective areas of South America, Africa, and the Atlantic Ocean near the equator. The COF of SEVIRI was relatively higher in the mid- and high-latitude regions, where the satellite zenith angle of Meteosat-10 became larger. Except for some desert regions, positive values appear to dominate the COF difference map between SEVIRI and CPR over all areas, particularly showing larger positive bias on the South Atlantic Ocean, most oceans of the Northern Hemisphere, and over Eastern Europe, which indicates that CPR detected fewer clouds than SEVIRI. The difference in the COF between SEVIRI and CALIOP was smaller. CALIOP captured higher frequency in the tropical region. In contrast, SEVIRI detected a slightly higher amount of clouds than CALIOP in mid- and high-latitude regions.
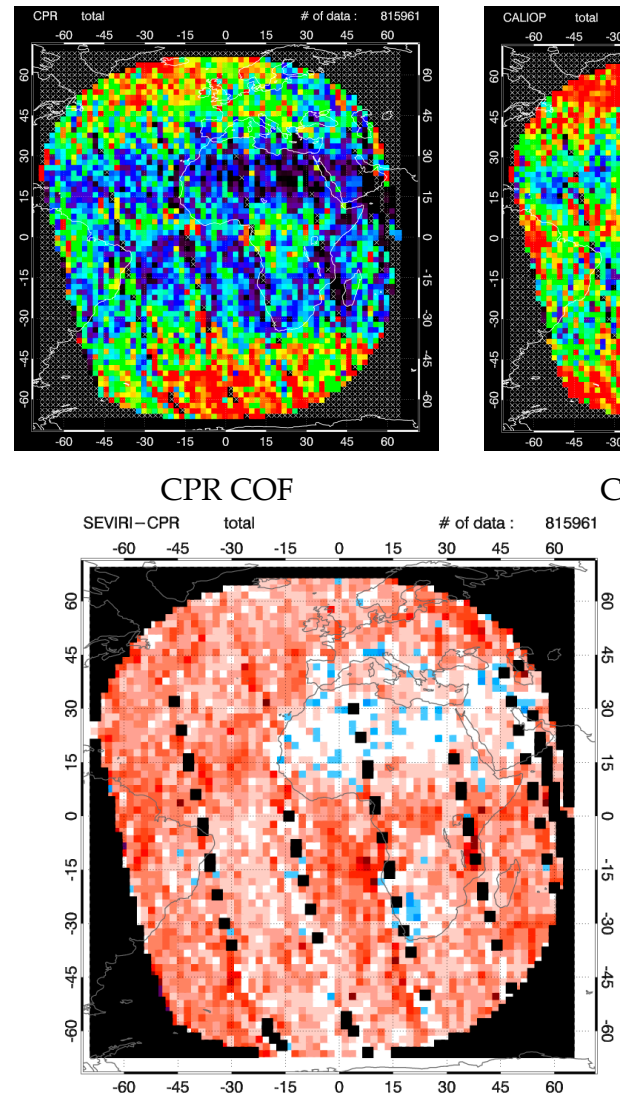

COF difference (SEVIRI-CPR)

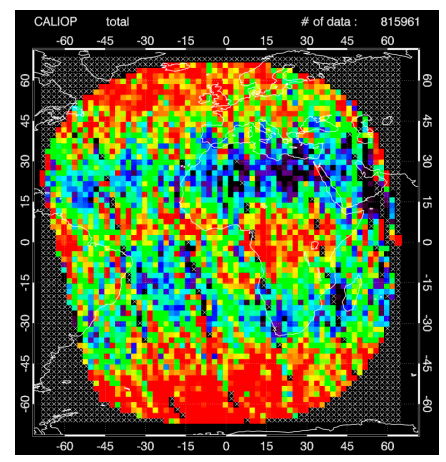

CALIOP COF

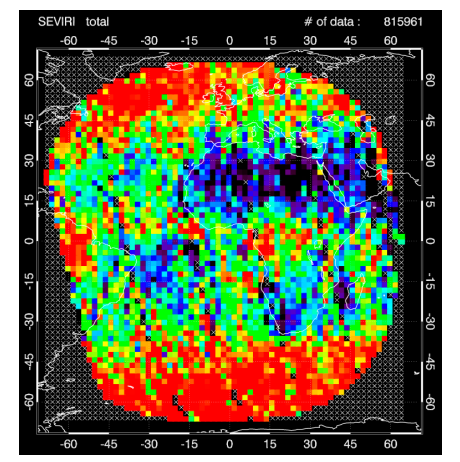

SEVIRI COF

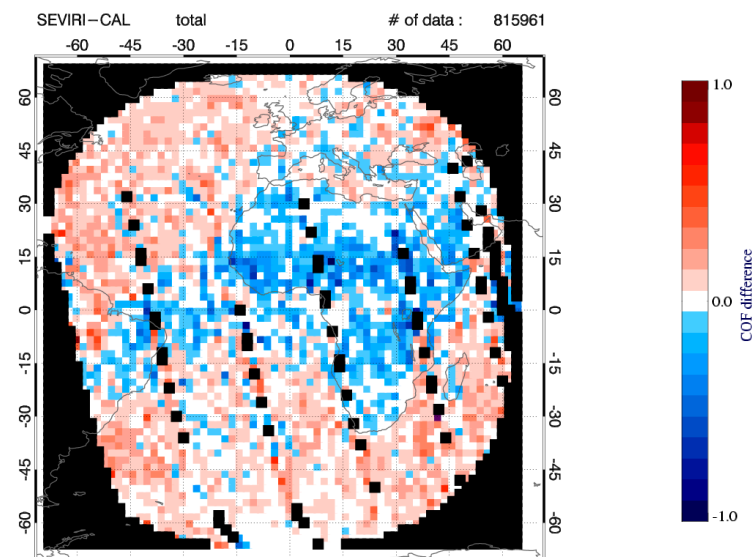

COF difference (SEVIRI-CALIOP)

Figure 1. Cloud occurrence frequency maps for Cloud Profiling Radar (CPR), Cloud-Aerosol LiDAR with Orthogonal Polarization (CALIOP), and Spinning Enhanced Visible and Infrared Imager (SEVIRI; upper panels) and the difference maps of SEVIRI compared with CPR and CALIOP products (lower panels) for a one year comparison period between May 2013 and April 2014. The brightness and the colours represent averaged values over a $2^{\circ}$ latitude $\times 2^{\circ}$ longitude grid box.

In order to investigate the seasonal COF changes, COF distributions for a boreal summer month (July 2013) and a boreal winter month (December 2013) are shown in Figure 2. We selected the December data because of the lack of data for January and February. For these maps, all possible observations were used from 11 to 31 July and from 1 to 31 December. In July, the cloud belt of the ITCZ was located near $0^{\circ}-10^{\circ} \mathrm{N}$, and the cloud-free zones were distributed broadly within the 
north and south boundaries of the ITCZ related to the subtropical ridges. Very low COF regions are shown through the Sahara Desert, the Mediterranean, and the Middle East, and over southern Africa including Kalahari. Moreover, high COF zones occurred over the Eastern Atlantic over the Sub-Tropical High. This COF pattern was more noticeable in SEVIRI data than those of CPR and CALIOP. In December, the ITCZ moved to the south, and the contrast of cloudy and clear zones were weakened. The COFs increased over southern Africa and South America, where they were very low in summer. These seasonal COF changes were generally shown on all products from SEVIRI, CPR, and CALIOP, although some systematic differences were noted in the frequency values. As mentioned in relation to Figure 1, SEVIRI detected significantly more clouds than CPR over the ocean regardless of the season, except for the constant cloud-free region. CALIOP estimated the cloudy region more widely near the ITCZ, whereas SEVIRI showed a lower frequency in this area. This tendency was more clearly observed over ocean than over land. In addition, SEVIRI caught more clouds where the satellite zenith angle of Meteosat-10 became larger, which was more evident in the winter hemisphere compared with the CPR COFs.

(a) July
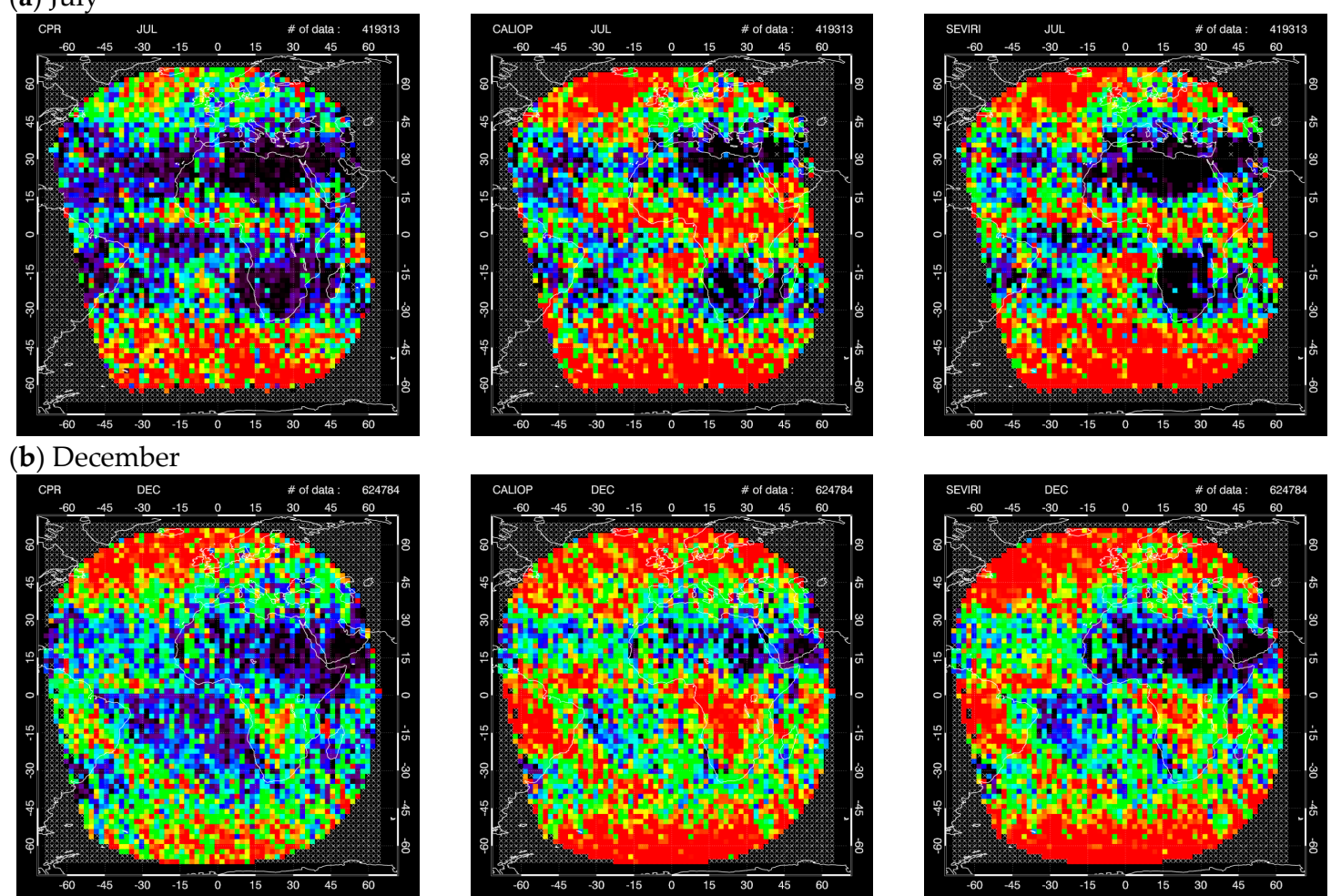

CPR COF

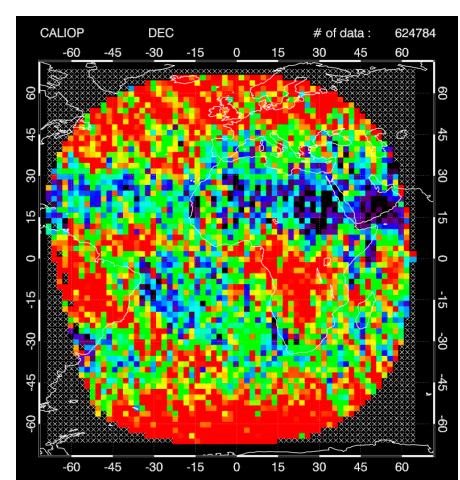

CALIOP COF

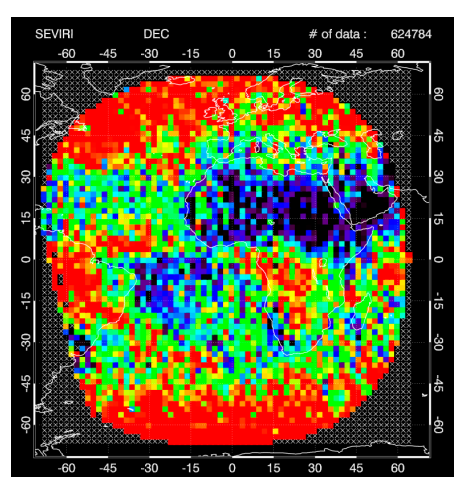

SEVIRI COF

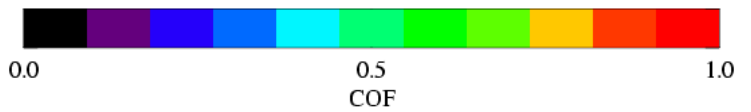

Figure 2. Cloud occurrence frequency maps for Cloud Profiling Radar (CPR), Cloud-Aerosol LiDAR with Orthogonal Polarization (CALIOP), and Spinning Enhanced Visible and Infrared Imager (SEVIRI). The upper panel (a) is from 11 to 31 July 2013, and the lower panel (b) is from 1 to 31 December 2013.

\subsection{Cloud-Top Height}

By utilizing AVAC-S, it is possible to plot all of the CTHs within the matchup dataset in the same figure, as demonstrated in the cross-section plot in Figure 3, which shows a section of CPR overpass 37,288 on 1 May 2013. CPR reflectivity is represented in the figure by coloured contours. The CALIOP results are represented by CTH values in dark green triangles, and white and red crosses indicate the 
CTHs from CPR and SEVIRI, respectively. CALIOP is highly sensitive to small ice cloud particles and optically thin clouds, and therefore detects higher CTHs. A broad distribution of thin cirrus clouds just below the tropopause is clearly shown in the CALIOP CTHs. The CPR CTHs are plotted along the top of the CPR reflectivity contour. SEVIRI retrieved similar but slightly lower CTHs than those from CPR for convective clouds, where the CPR reflectivity became strong. SEVIRI captured some portion of thin cirrus clouds detected by CALIOP. However, it also produced CTHs in the middle of the troposphere below very thin cirrus clouds because they did not sufficiently affect the SEVIRI radiances.

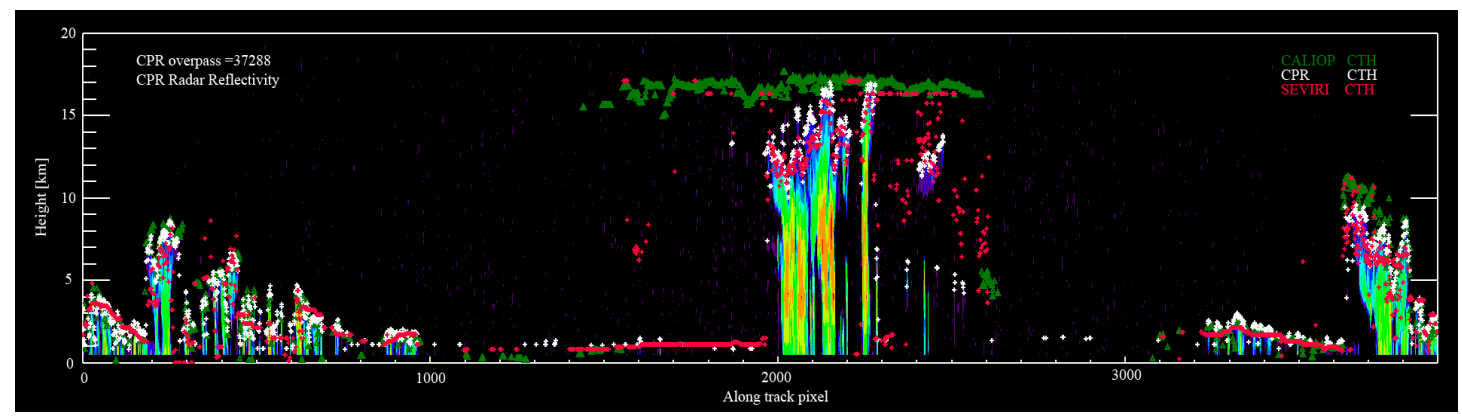

Figure 3. Colour-coded Cloud Profiling Radar (CPR)-derived radar reflectivity and cloud-top heights (CTHs) along CPR overpass 37,288 on 1 May 2013. CTHs from Cloud-Aerosol LiDAR with Orthogonal Polarization (CALIOP), CPR, and Spinning Enhanced Visible and Infrared Imager (SEVIRI) are plotted as dark green triangles and white and red crosses, respectively.

The CTH comparison among SEVIRI, CPR, and CALIOP was conducted by using the same matchup dataset as that was used in the COF analysis. In total, 329 CPR overpasses were selected. The spatial distribution of the matchup data is shown in Figure 4a. The data points are well distributed over the Meteosat-10 observation disk. Figure $4 b, c$ show comparisons of SEVIRI CTHs with CPR and CALIOP, where the values were filtered by the spatial uniformity test and quality control threshold test using the CTH variance from SEVIRI algorithm for more rigorous analysis of the SEVIRI CTH product. In the case of the comparison with CPR, the total number of matchup data for which both CPR and SEVIRI had valid CTH values was 346,287. Applying the spatial uniformity filter, 217,895 (63\%) data points were selected. After the CTH variance test, 193,555 data points were finally selected. That is, approximately $44 \%$ of the collocated data were eliminated by this data filtering process for rigorous quality control. The use of these filters removes some cases with small clouds and/or multi-layer cloud scenes. However, if these filters were not used, then issues related to establishing meaningful collocations (i.e., only using data where both SEVIRI and A-Train sensors are directed to the same clouds) would mean that the comparison dataset was too noisy to be useable.

On the scatter plot of CTH retrieved from the SEVIRI algorithm against CALIOP measurements (Figure 4c), a large scatter of data points is shown. SEVIRI produced lower CTHs around 1-2 km, although CALIOP retrieved them as mid- or high-level clouds. This occurred mainly because the data corresponding to thin cirrus clouds, as previously shown in Figure 3, can be regarded as different clouds effectively measured by SEVIRI and CALIOP in this case. The data count density showed larger scattering than with CPR, where the axis of major density departed from the complete one-to-one matching line towards the lower SEVIRI values. The distribution was slightly broader with a correlation coefficient of 0.78 , a bias of $-1.61 \mathrm{~km}$ (i.e., the lower SEVIRI CTH), and a standard deviation of $3.24 \mathrm{~km}$ from 220,199 data points. The bias appeared to be larger for higher clouds, whereas better coherence was shown for low clouds between the CALIOP and SEVIRI CTHs. Moreover, the scatter plot was relatively distinct between the CPR and SEVIRI CTH products with a correlation coefficient of 0.92 , a bias of $-0.20 \mathrm{~km}$ (SEVIRI low), and a standard deviation of $1.67 \mathrm{~km}$. The frequency was less than for the CALIOP comparison, although low SEVIRI CTH outliers were still detected. The discontinuity of the SEVIRI CTH distribution occurred near $5 \mathrm{~km}$ in height, which resulted from the SEVIRI CTH 
algorithm that selectively used the MR or SL methods near $480 \mathrm{hPa}$. As shown in Figure 4, average CTHs derived from SEVIRI are closer to CPR measurements than to CALIOP measurements. Thus, further comparisons with CPR products were conducted.

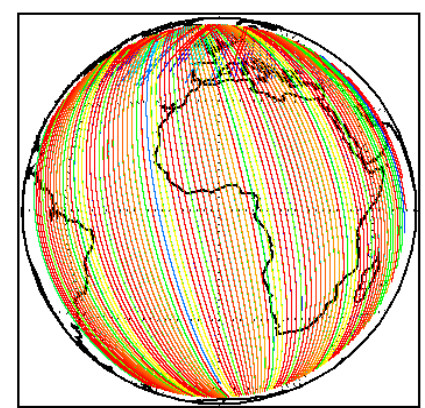

(a)

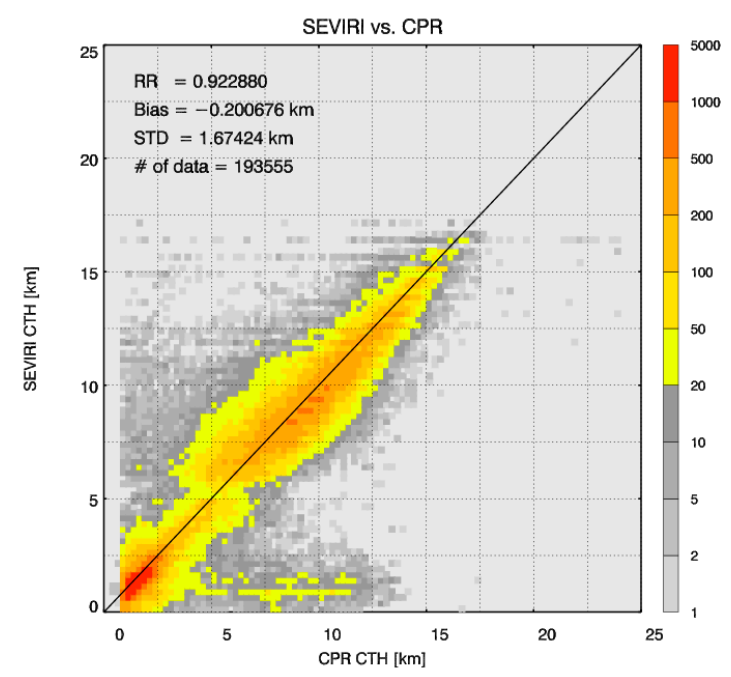

(b)
Total 329 CPR overpasses from May 2013 to April 2014

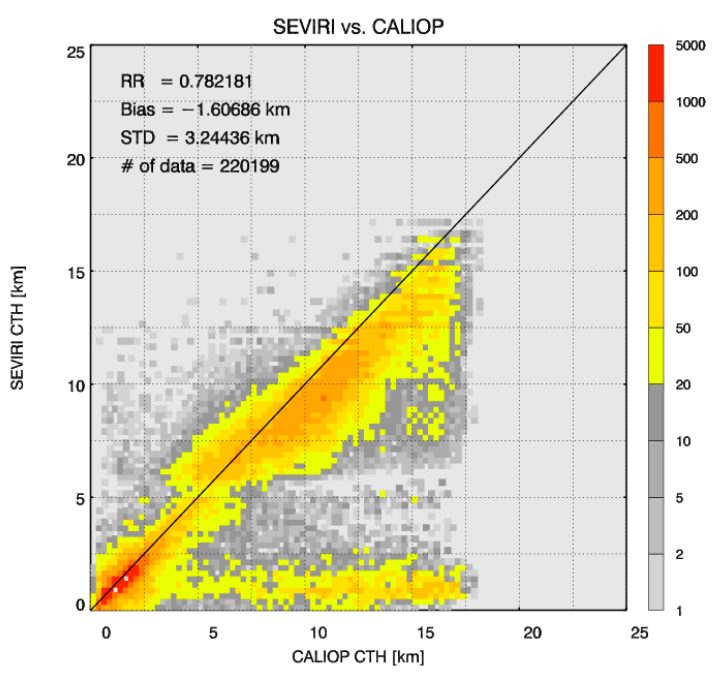

(c)

Figure 4. (a) Geographical distribution of collocation dataset used in this study and scatter plots for Spinning Enhanced Visible and Infrared Imager (SEVIRI) cloud-top height (CTH) with comparison to (b) Cloud Profiling Radar (CPR) CTH and (c) Cloud-Aerosol LiDAR with Orthogonal Polarization (CALIOP) CTH.

Observed and simulated clear sky radiances differ because of the cumulative effects of instrument noise, spectral response function errors, inadequate knowledge of the atmospheric and surface state, and radiative model approximations. Thus bias corrections are critical for the proper use of infrared channels for cloud height estimation [23]. Hewison and Muller [24] reported ice contamination of the SEVIRI sensor, which causes a change in the spectral response as well as the sensitivity of the detector. They found that the $\mathrm{CO}_{2}$ channel had a significant sensitivity to ice contamination and showed larger bias. The UK Met Office has monitored the satellite observed radiances and adapted the monitoring results periodically for operational product retrievals and NWP applications. During the period analysed in this study, the SEVIRI $\mathrm{CO}_{2}$ channel bias correction increment (BC) was updated three times for SEVIRI CTH processing: on 10 July, 24 September, and 15 November 2013. Figure 5 shows the time series of SEVIRI CTH validation scores compared with CPR CTHs. The uppermost dotted line represents the standard deviation; the solid line in the middle represents the correlation coefficient; and the dashed line at the bottom shows the bias. The number of data used for each validation is shown as a bar graph. Constant and good correlation scores of 0.9 were noted during the validation period. However, the variation of bias score was outstanding along with the changes in $\mathrm{CO}_{2}$ $\mathrm{BC}$ value. Prior to the update in July, when the $-1.15 \mathrm{~K} \mathrm{CO}_{2} \mathrm{BC}$ increment was used, SEVIRI CTHs 
had larger negative biases of approximately $-0.5 \mathrm{~km}$. The biases increased to positive values after the large BC change to $0.85 \mathrm{~K}$ in July. Note that the data on 10 July are the results from Meteosat-9 instead of Meteosat- 10 because of its decontamination process. The $\mathrm{CO}_{2} \mathrm{BC}$ change in September from $0.85 \mathrm{~K}$ to $-0.15 \mathrm{~K}$ led to a decrease in the bias values down to about $-0.25 \mathrm{~km}$. Moreover, another change to $-0.65 \mathrm{~K}$ in November enhanced the negative biases slightly larger, but to make correlation coefficient and standard deviation slightly better as 0.93 and 1.61, respectively. Without the large variability of biases and standard deviations shown in January and February, when small numbers of data were collected, SEVIRI produced CTHs with more stable bias compared to CPR CTHs. The variation of the standard deviation score is not apparent relative to the $\mathrm{CO}_{2} \mathrm{BC}$ changes, although it fluctuated slightly more between September and November.

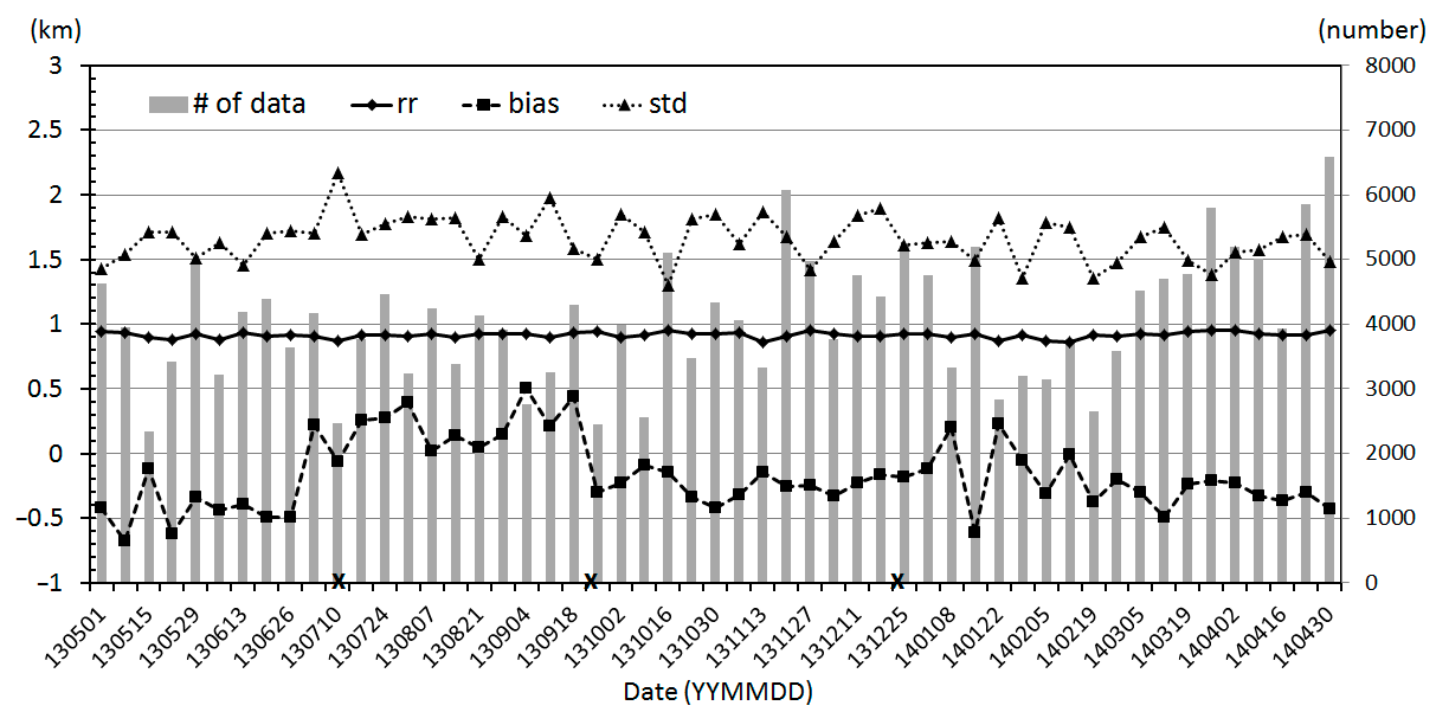

Figure 5. Time series of the daily validation scores of standard deviation (STD; dotted line), correlation coefficient (solid line), and bias (dashed line) from May 2013 to April 2014. The number of validation data (grey bar) from the cloud-top height (CTH) comparison between the Spinning Enhanced Visible and Infrared Imager (SEVIRI) and Cloud Profiling Radar (CPR) products is also shown. Black x marks on the $\mathrm{x}$-axis indicate the dates the bias correction was updated.

To investigate the effect of $\mathrm{CO}_{2} \mathrm{BC}$ updates on $\mathrm{CTH}$ retrieval, the $\mathrm{CTH}$ results derived from SEVIRI applying the previous and the updated $\mathrm{BC}$ values are shown in Figure 6. Figure 6 shows a section of CPR overpass 39,413 , when $\mathrm{CO}_{2} \mathrm{BC}$ increment was updated from $0.85 \mathrm{~K}$ to $-0.15 \mathrm{~K}$ on 24 September 2013. The cross-section plots are the same types as those in Figure 3, although the figures in the left-hand (right-hand) panel represent the results prior to (following) the BC update. The CPR reflectivity and the CTHs from CALIOP and CPR are the same in both panels, and the SEVIRI CTHs (red crosses) changed as expected. In Figure 6, it is clear that the SEVIRI CTHs became lower owing to the decrease in the $\mathrm{CO}_{2} \mathrm{BC}$ value by $1 \mathrm{~K}$, from $0.85 \mathrm{~K}$ to $-0.15 \mathrm{~K}$. The heights of low clouds that might be determined by the SL method showed no apparent change, although those for the middle and high clouds, which are generally assigned by the MR method, decreased. The decrease in the mid-level SEVIRI CTHs is remarkable, and it is evident that the BC update led to better results. The problematic mid-level clouds appear to have disappeared after this update. This shows BC change can affect the choice of method between MR and SL in the CTH algorithm. However, the underestimation of CTHs over the deep convective clouds became slightly larger compared to CPR CTHs. Figure 7 shows the scatter plots of CTH from SEVIRI against CPR for each $\mathrm{CO}_{2}$ channel $\mathrm{BC}$ value. The $\mathrm{CTH}$ changes with $\mathrm{BC}$ values are clear in these plots as well. Prior to the $\mathrm{BC}$ change, the distribution of CTHs showed more data points on the lower right-hand side of the one-to-one line in which SEVIRI CTHs showed a slightly large negative bias of $-0.45 \mathrm{~km}$ (Figure $7 \mathrm{a}$ ). A large increase 
in the SEVIRI CTHs is shown in Figure 7b, which resulted in a positive bias of $0.22 \mathrm{~km}$ with apparent discontinuity at about $5 \mathrm{~km}$ in height. The next two changes resolved these issues, making the SEVIRI CTHs more reliable. The correlation coefficients and the standard deviations did not significantly vary from the BC update. Since the BC increment was updated to $-0.65 \mathrm{~K}$ in November 2013, SEVIRI has produced more stable values compared to the CPR CTHs, with a correlation coefficient of 0.93 , bias of $-0.27 \mathrm{~km}$, and standard deviation of $1.61 \mathrm{~km}$. Thus, it is evident that the $\mathrm{CO}_{2} \mathrm{BC}$ increment is critical and needs to be carefully selected in the SEVIRI CTH algorithm.

Overpass 39413 (24 September 2013)
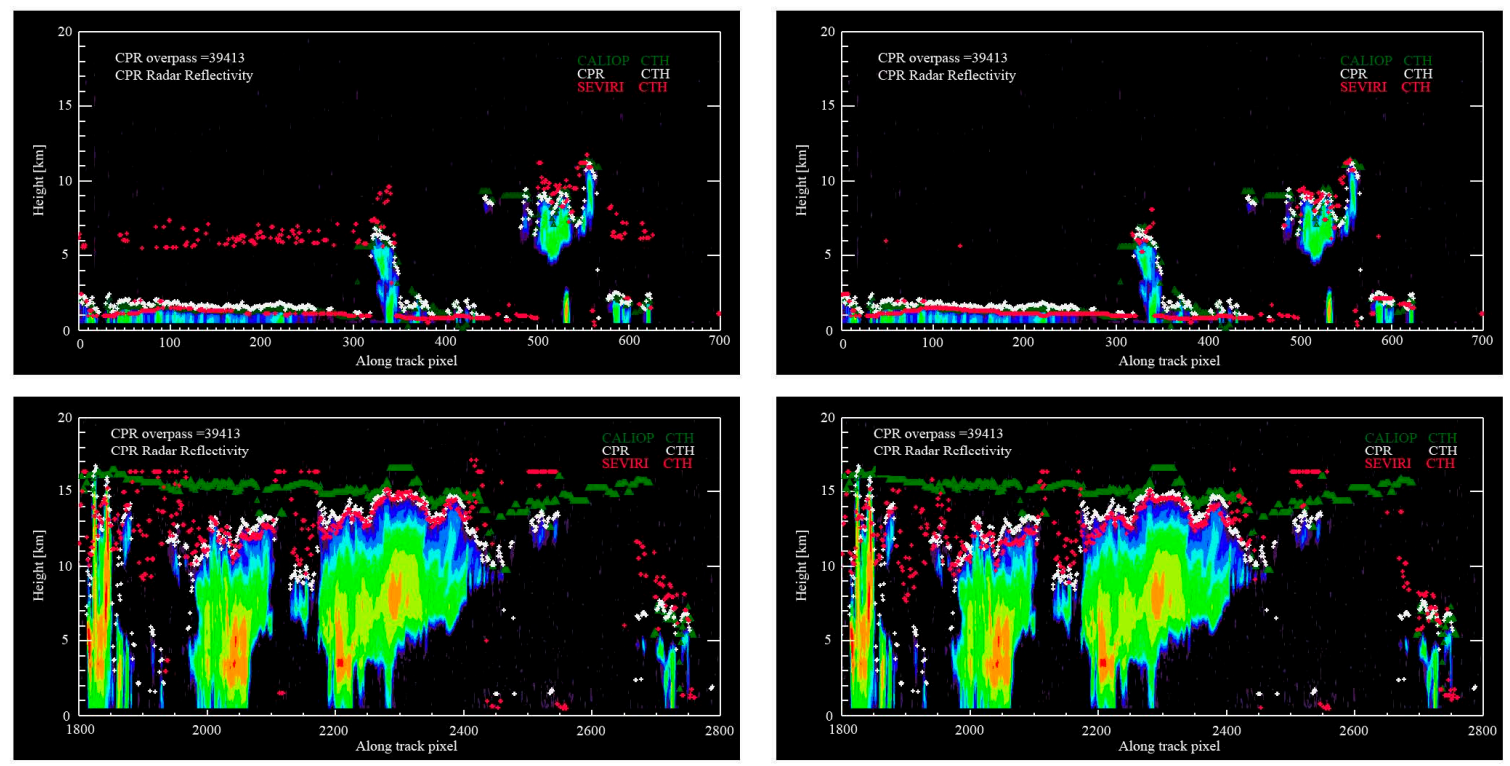

$\mathrm{CO}_{2} \mathrm{BC}: 0.85$

$\mathrm{CO}_{2} \mathrm{BC}:-0.15$

Figure 6. Comparison of Spinning Enhanced Visible and Infrared Imager (SEVIRI) cloud-top heights (CTHs) derived by using different $\mathrm{CO}_{2}$ bias correction increment (BC) values. The left-panels show the results derived by using the $\mathrm{CO}_{2} \mathrm{BC}$ values prior to the update, and the right-hand panel shows the CTH derived afterward for CPR (Cloud Profiling Radar) overpass 39,413 on 24 September 2013. CTHs from Cloud-Aerosol LiDAR with Orthogonal Polarization (CALIOP), CPR, and SEVIRI are plotted as dark green triangles and white and red crosses, respectively.

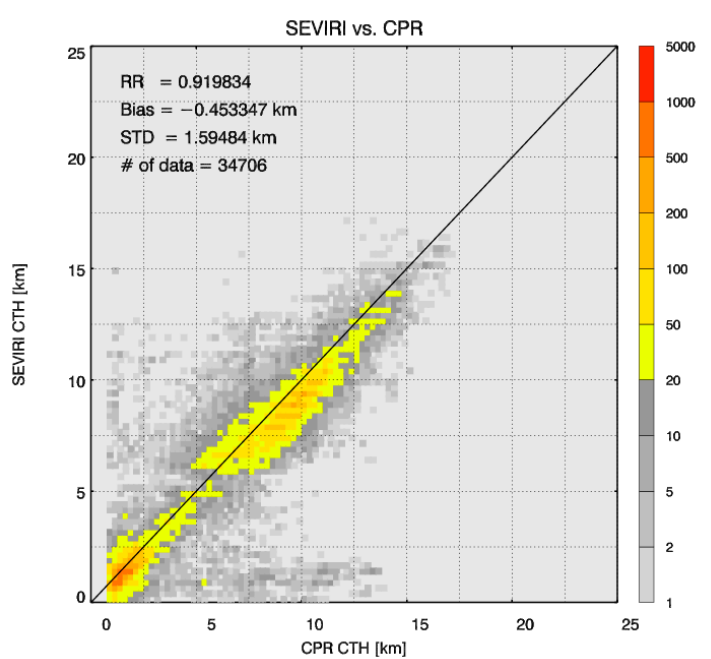

(a)

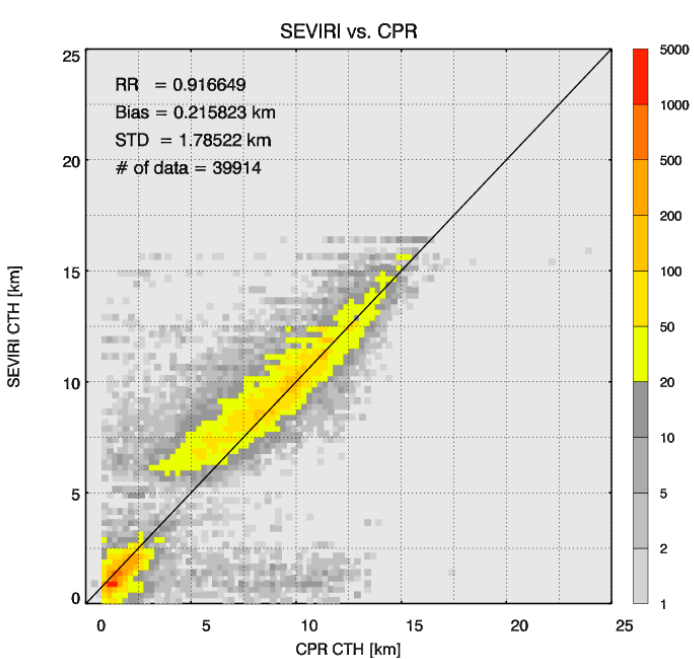

(b)

Figure 7. Cont. 


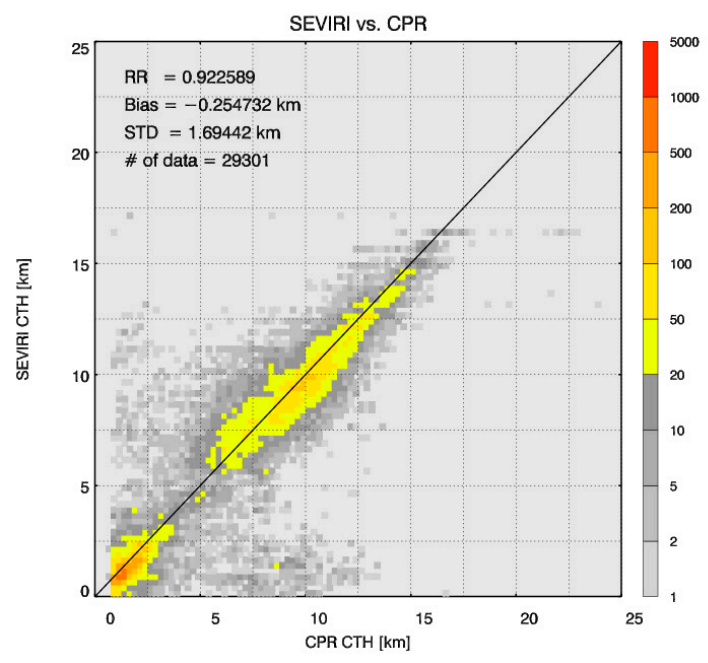

(c)

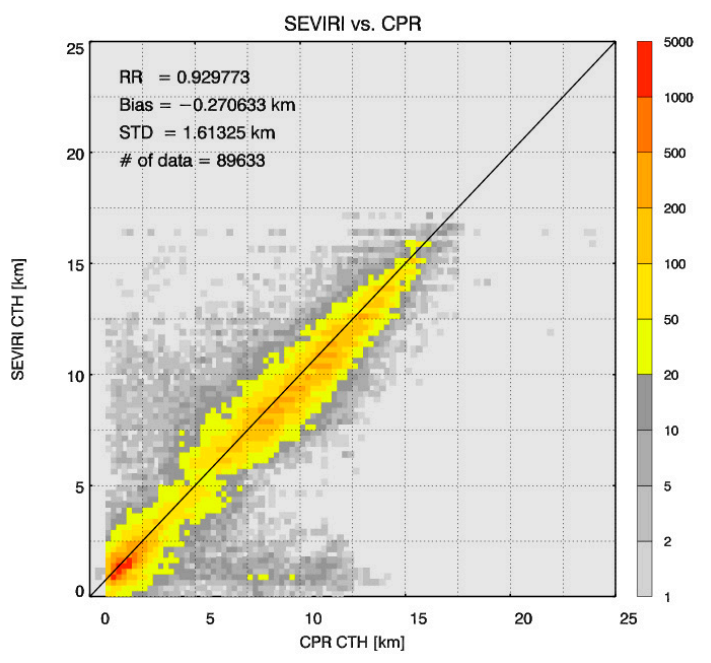

(d)

Figure 7. Spinning Enhanced Visible and Infrared Imager (SEVIRI) cloud-top height (CTH) scatter plots compared with Cloud Profiling Radar (CPR) CTH for each period used a different $\mathrm{CO}_{2}$ bias correction increment. The periods and $\mathrm{CO}_{2}$ increment values are (a) 1 May-26 June 2013, $\mathrm{CO}_{2} \mathrm{BC}$ : $-1.15 \mathrm{~K}$; (b) 17 July-18 September 2013, CO 2 BC: $0.85 \mathrm{~K}$; (c) 25 September-13 November 2013, $\mathrm{CO}_{2}$ BC: $-0.15 \mathrm{~K}$; and (d) 20 November 2013-30 April 2014, $\mathrm{CO}_{2} \mathrm{BC}:-0.65 \mathrm{~K}$.

\section{Discussion}

\subsection{Cloud Occurrence Frequency}

The COF distributions analysed here show consistency with previous studies. For example, Hartmann et al. [25] used one year of International Satellite Cloud Climatology Project (ISCCP) data from March 1985 to February 1986 and analysed the cloud types categorised by cloud-top pressures into high, middle, and low clouds using intermediate boundaries of $440 \mathrm{hPa}$ and $680 \mathrm{hPa}$, and by cloud optical thickness into optically thin and thick clouds using 9.38 as a reference. They reported that high-cloud types occurred preferentially where convection occurred in the tropics and in mid-latitude storm tracks. In addition, they found that low clouds were predominant over ocean and were most abundant in the subtropical eastern oceans, where the sea surface temperature is comparatively low and the mean air motion is downward. Total cloud cover was the greatest over high-latitude oceans, where stratus regimes are dominant, and in regions of intense tropical convection. They also showed that thin, high-level cloud frequency features decreased in summer relative to winter over the Atlantic Ocean, Africa, and Europe for the Meteosat-10 observation area [25] (Figures 2 and 3). Wang et al. [26] investigated the spatial and temporal variability of sub-visual clouds (SVC) and opaque clouds by using Stratospheric Aerosol and Gas Experiment (SAGE) II data from 1985-1990. They found that the latitudinal movements of the tropical maxima are in concert with the seasonal shift of the ITCZ. Cloud occurrence in the subtropical regions has a distinct seasonal variation, with maximum frequency in local summer and minimum during local winter. However, for the Meteosat- 10 observation area, a slight decrease of SVC occurrence was found [26] (Plate 2). Similar cloud spatial variability was reported in sequential papers of Wylie [27-29]. Three COF cloud products investigated in this study showed similar spatial distribution and variability to the previous studies, although some systematic differences were noted in COF values. The difference shown in the statistical scores can be attributed to the different characteristics and sensitivity of the sensors. CALIOP is more sensitive to the small ice particles in clouds because it uses beams at a shorter wavelength of $532 \mathrm{~nm}$. Thus, it senses thin, high-level cloud much better than the other sensors. On the contrary, CPR, which uses a microwave wavelength of $3.2 \mathrm{~mm}(94 \mathrm{GHz})$, is effective in detecting rain droplet-size cloud water particles. It is essentially insensitive to very thin cirrus clouds, which have small sizes and low concentrations of 
ice crystals, because the radar backscatter in the cirrus volume is insufficient for generating a return signal that rises above the CPR detection threshold. CPR is also relatively ineffective for detecting clouds in the lowest kilometre of the atmosphere owing to radar contamination from ground clutter. As indicated by the different characteristics of various sensors, SEVIRI detects clouds over a wider area than CPR, and it shows lower COFs than CALIOP near the ITCZ and mid-latitudes, where thin, high clouds containing small ice particles are dominant. The COF difference between the SEVIRI and the CALIOP products decreases in summer, particularly for thin, high-level clouds of the Meteosat-10 area, as shown in previous studies. In this study, we found that the UK Met Office SEVIRI algorithm detects clouds very strictly over the ocean surface with mean COF of $64.32 \%$, which is even larger than CALIOP products $(63.65 \%)$. Over estimation of SEVIRI COF is dominant over the high-latitude oceans, where the satellite zenith angle of Meteosat-10 became larger. On the contrary, SEVIRI algorithm has a relative weakness in detecting clouds over the land surface with the COF bias of $-12.14 \%$ compared to CALIOP products. From passive infrared measurements, the cloud detection of low level clouds over land is challenging for the following reasons: first, the thermal contrast between them and the surface is small. Second, surface type, emissivity and temperature in the satellite field of view are complex and inhomogeneous, which is normally neglected in the cloud detection algorithm. Thus, further investigation is required for cloud detection over land.

\subsection{Cloud-Top Height}

The CTH comparison results in this study are in line with those from previous research. Weisz et al. [30] compared AIRS and MODIS CTH retrievals with CALIOP and CPR products using the data on 22 July 2006 when the scenes include various cloud types. They found the CTH retrieved from AIRS and MODIS agree well in general, and these retrievals are closer to the values obtained by CPR than the ones obtained by CALIOP. They also noted that the ability to retrieve CTH of optically thin cirrus clouds and very low clouds is limited due to the nature of infrared measurements. Holz et al. [31] investigated the difference between MODIS and CALIOP CTH for the months of August 2006 and February 2007. They found that the MODIS CTH was $2.6 \pm 3.9 \mathrm{~km}$ lower than the CALIOP products. The mean differences were larger than $4 \mathrm{~km}$ for optically thin high clouds. The large CTH differences were observed mainly for high thin cirrus clouds in the equatorial region. They noted that CTH bias depended on the CALIOP product resolution used in the comparison. The 5-km CALIOP averaged product (same resolution as we used in this study) is more sensitive to optically thin clouds than the 1-km product because the signal-to-noise ratio increases through horizontal averaging of CALIOP LiDAR shots. Hence, the higher clouds are detected in the 5-km CALIOP product and the CTH difference to the data from infrared passive sensor becomes larger. Hamann et al. [3] compared ten SEVIRI CTH data sets retrieved from Meteosat-9 satellite observations from ten retrieval algorithms of different institutes in Europe and the USA and validated them with products from CALIOP and CPR by using the five golden day datasets in 2008. In their research, the correlations of the SEVIRI datasets with CALIOP and CPR measurements were between 0.77 and 0.90, and the mean SEVIRI CTHs were 1.1 to $2.5 \mathrm{~km}$ lower than the CALIOP measurement, as CALIOP is more sensitive to optically thin clouds. The differences between the SEVIRI and the CPR CTHs ranged from -0.8 to $0.6 \mathrm{~km}$. They also validated $\mathrm{CTH}$ retrievals for three different cloud regimes: optically thick and thin single layer clouds and multi-layer clouds. They found that the correlation coefficients were generally above 0.95 and the biases were on the order of a few hundred metres, but the retrieval uncertainties for optically thin clouds and multi-layer clouds became greater.

In this study, we investigated the CTH accuracy derived from SEVIRI measurements on board Meteosat-10 in the UK Met Office for a longer time period (one year). We found that the SEVIRI CTH products showed similar characteristics to the products from CALIOP and CPR measurements. The overall statistics showed a bias of $-1.61 \mathrm{~km}$ and a standard deviation of $3.24 \mathrm{~km}$ compared to CALIOP CTH, and a bias of $-0.20 \mathrm{~km}$ and a standard deviation of $1.67 \mathrm{~km}$ compared to CPR products. The difference of these statistics from those in Hamann [3]'s study is within the 
acceptable limits considering the difference in the study period, satellites (Meteosat-9 and Meteosat-10), and the filters used. The visual inspection of comparison plots for many different times and locations suggests that the bias tends to be larger for optically thin clouds and multi-layer clouds than for well-defined single-layer clouds. The reason is that the UK Met Office SEVIRI algorithm assumes a single layer cloud when retrieving CTH similar to many other CTH algorithms for passive infrared measurements. To improve the CTH retrieval for these cloud situations, further research is needed in multi-layer approaches suggested by Pavolonis and Heidinger [32], Minnis et al. [33], and recently by Watts et al. [34] for SEVIRI retrievals. In this study, we also found that CTH derived from SEVIRI measurements depended on the $\mathrm{CO}_{2}$ channel bias correction increment used in the algorithm. Therefore, careful treatment of the bias correction values is required.

\section{Summary and Conclusions}

This study investigated the characteristics of the UK Met Office SEVIRI products of COF and $\mathrm{CTH}$ conducting an inter-comparison of the cloud products from the CPR and the CALIOP on board the A-Train constellation. The evaluation was made on the basis of 329 CPR overpasses allowing for approximately 800,000 individual matchups among the CPR, CALIOP, and SEVIRI products for one year from May 2013 to April 2014. Due to the CPR data availability, only daytime products were compared in this study. The COFs showed good agreement in terms of spatial distribution and temporal variability despite systematic biases, which are expected due to the differences in observation and instrument characteristics of the three sensors. The distribution and variability of the SEVIRI COFs were also consistent with previous studies. CALIOP detected clouds most sensitively and widely, followed by SEVIRI, with a mean frequency difference of $-3.90 \%$ in COF. The CPR showed less sensitivity with a COF $14.35 \%$ lower than that for SEVIRI. Particularly over the tropics, it is outstanding that the CALIOP COFs showed high frequency and were distributed over the large area near the ITCZ. This can be attributed to CALIOP's high sensitivity to clouds with small ice particles and low optical thickness, which are not enough to be sensed by other sensors. The seasonal variability of the three products showed a similar pattern of decline in summer and an increase in winter. These results suggest that SEVIRI COFs are reliable. However, SEVIRI detected clouds more strictly over oceans (with $64.32 \%$ of SEVIRI COF which is $17.28 \%$ and $0.67 \%$ higher than those from CPR and CALIOP products, respectively) with relatively less effectiveness over the land surface $(44.74 \%$ of SEVIRI COF with $9.07 \%$ and $-12.14 \%$ biases against CPR and CALIOP COFs, respectively), where accurate cloud retrievals from passive infrared measurement are challenging.

This study also investigated the CTH retrievals by the UK Met Office SEVIRI algorithm compared to CALIOP and CPR products. Differences among the products in the CTH analysis were also noted. The high sensitivity to thin, high clouds of CALIOP was apparent, which generated a larger scatter in the plots of CTH retrieved by the SEVIRI algorithm against CALIOP measurements. The majority of the scatter points were on the lower right-hand side of the one-to-one line, meaning that the CTH retrieved by the SEVIRI algorithm was lower than the CALIOP CTH. Some points were retrieved by SEVIRI as lower clouds with around 1-2 km CTH while CALIOP retrieved them as mid- or high-level clouds. The mean SEVIRI CTHs were $1.61 \mathrm{~km}$ lower than CALIOP measurements with a correlation coefficient of 0.78 . The average CTHs derived from SEVIRI were closer to CPR products with a correlation coefficient of 0.92 and a bias of $-0.20 \mathrm{~km}$. Thus, further analysis was conducted with the CPR products. Considering that the $\mathrm{CO}_{2}$ channel $\mathrm{BC}$ used in the SEVIRI CTH retrieval algorithm was updated periodically through radiance monitoring, the effect of these $\mathrm{BC}$ changes was analysed. The results showed that the SEVIRI CTHs derived by the MR method were highly sensitive to $\mathrm{CO}_{2}$ $\mathrm{BC}$ values. The correlation and STD did not change much, but the retrieved CTH changed noticeably with $\mathrm{CO}_{2} \mathrm{BC}$ updates with the bias ranging from -0.7 to $0.5 \mathrm{~km}$. The first update of $\mathrm{CO}_{2} \mathrm{BC}$ value from $-1.15 \mathrm{~K}$ to $0.85 \mathrm{~K}$ led to an increase in $\mathrm{CTH}$ values up to about $0.67 \mathrm{~km}$ in mean CTH values. Since the BC update in November 2013, SEVIRI has produced more stable CTHs compared with the CPR CTHs, with a correlation coefficient of 0.93 , bias of $-0.27 \mathrm{~km}$, and standard deviation of $1.61 \mathrm{~km}$. 
This study found that the bias correction values need to be carefully monitored and selected when the CTH algorithm is applied with simulated and observed radiance comparison.

Acknowledgments: This study was performed through collaboration of the UK Met Office and Korea Meteorological Administration (KMA). This research was supported by the National Meteorological Satellite Center (Project No. 153-3100-3137-305-210-13) of KMA and the work of Jhoon Kim was supported by the project titled 'Research for Applications of Geostationary Ocean Color Imager' (Project No. 1525004803), funded by the Ministry of Oceans and Fisheries, Korea. This work made use of the AVAC-S software owned by EUMETSAT and developed by Informus $\mathrm{GmbH}$. Further information on AVAC-S can be obtained at https://angel1.projectlocker.com/informus/EUM839/trac/wiki.

Author Contributions: Chu-Yong Chung, Peter N. Francis, and Roger W. Saunders conceived and designed the experiments; Chu-Yong Chung performed the experiments; Chu-Yong Chung and Peter N. Francis analysed the data; Peter N. Francis contributed materials/analysis/tools; Roger W. Saunders and Jhoon Kim took part in the discussion of the presented work; Chu-Yong Chung wrote most of the manuscript.

Conflicts of Interest: The authors declare no conflict of interest.

\section{References}

1. Intergovernmental Panel on Climate Change. Climate Change. The Scientific Bases: Contribution of Working Group I to the Third Assessment Report of the International Panel on Climate Change (IPCC); Cambridge University Press: Cambridge, UK, 2001.

2. Liou, K.M. Influence of cirrus clouds on weather and climate processes: A global perspective. Mon. Weather Rev. 1986, 114, 1167-1198. [CrossRef]

3. Hamann, U.; Walther, A.; Baum, B.; Bennartz, R.; Bugliaro, L.; Derrien, M.; Francis, P.N.; Heidinger, A.; Joro, S.; Kniffka, A.; et al. Remote sensing of cloud top pressure/height from SEVIRI: Analysis of ten current retrieval algorithms. Atmos. Meas. Tech. 2014, 7, 2839-2867. [CrossRef]

4. Saunders, R.W.; Francis, R.; Francis, P.N.; Crawford, J.; Smith, A.; Brown, I.; Taylor, R.; Forsythe, M.; Doutriaux-Boucher, M.; Millington, S. The exploitation of Meteosat Second Generation data in the Met Office. In Proceedings of the 2006 EUMETSAT Meteorological Satellite Conference, Helsinki, Finland, 12-16 June 2006.

5. Wolters, E.L.A.; Roebeling, R.A.; Feijt, A.J. Evaluation of cloud-phase retrieval methods for SEVIRI on Meteosat-8 using ground-based lidar and cloud radar data. J. Appl. Meteorol. Clim. 2008, 47, 1723-1738. [CrossRef]

6. Illingworth, A.J.; Hogan, R.J.; O'Connor, E.J.; Bouniol, D.; Brooks, M.E.; Delanoe, J.; Donovan, D.P.; Eastment, J.D.; Gaussiat, N.; Goddard, J.W.F.; et al. Cloudnet-Continuous evaluation of cloud profiles in seven operational models using ground-based observations. Bull. Am. Meteorol. Soc. 2007, 88, 883-898. [CrossRef]

7. Vanbauce, C.; Cadet, B.; Marchand, R.T. Comparison of POLDER apparent and corrected oxygen pressure to ARM/MMCR cloud boundary pressures. Geophys. Res. Lett. 2003, 30, 1212. [CrossRef]

8. Bennartz, R.; Fell, F.; Walther, A. AVAC-S: A-Train Validation of Aerosol and Cloud Properties from SEVIRI; EUMETSAT Document EUM-07-839-INF; EUMETSAT: Darmstadt, Germany, 2010.

9. Schmetz, J.; Pili, P.; Tjemkes, S.; Just, D.; Kerkmann, J.; Rota, S.; Ratier, A. An introduction to Meteosat Second Generation (MSG). Bull. Am. Meteorol. Soc. 2002, 83, 977-992. [CrossRef]

10. Saunders, R.W.; Kriebel, K.T. An improved method for detecting clear sky and cloudy radiances from AVHRR data. Int. J. Remote Sens. 1988, 9, 123-150. [CrossRef]

11. Saunders, R.W.; Matricardi, M.; Brunel, P. An improved fast radiative model for assimilation of satellite radiance observations. Q. J. R. Meteor. Soc. 1999, 125, 1407-1425. [CrossRef]

12. Hocking, J.; Francis, P.N.; Saunders, R.W. Cloud detection in Meteosat Second Generation imagery at the Met Office. Meteorol. Appl. 2011, 18, 307-323. [CrossRef]

13. Eyre, J.R.; Menzel, W.P. Retrieval of cloud parameters from satellite sounder data: A simulation study. J. Appl. Meteorol. 1989, 28, 267-275. [CrossRef]

14. Moseley, S. Changes to the Nimrod Cloud Top Height Diagnosis; Met Office Forecasting Research Technical Report No. 424; Met Office: Exeter, Devon, UK, 2003. 
15. Francis, P.N.; Hocking, J.A.; Saunders, R.W. Improved diagnosis of low-level cloud from MSG SEVIRI data for assimilation into Met Office limited area models. In Proceedings of the 2008 EUMETSAT Meteorological Satellite Conference, Darmstadt, Germany, 8-12 September 2008.

16. Stephens, G.L.; Vane, D.G.; Boain, R.J.; Mace, G.G.; Sassen, K.; Wang, Z.; Illingworth, A.J.; O'Connor, E.J.; Rossow, W.B.; Durden, S.L.; et al. The CloudSat mission and the A-Train: A new dimension of space-based observations of clouds and precipitation. Bull. Am. Meteorol. Soc. 2002, 83, 1771-1790. [CrossRef]

17. Stephens, G.L.; Vane, D.G.; Tanelli, S.; Im, E.; Durden, S.; Rokey, M.; Reinke, D.; Partain, P.; Mace, G.G.; Austin, R.; et al. CloudSat mission: Performance and early science after the first year of operation. J. Geophys. Res. 2008, 113, D00A18. [CrossRef]

18. Wang, Z.; Sassen, K. Level 2 Cloud Scenario Classification Product Process Description and Interface Control Document; Version 5.0; Cooperative Institute for Research in the Atmosphere, Colorado State University: Fort Collins, CO, USA, 2007; Available online: http:/ /www.cloudsat.cira.colostate.edu/sites/default/files / products/files/2B-CLDCLASS_PDICD.P_R04.20070724.pdf (accessed on 30 January 2016).

19. Marchand, R.; Mace, G.G.; Ackerman, T.; Stephens, G. Hydrometeor detection using CloudSat-An Earth-orbiting 94-GHz Cloud Radar. J. Atmos. Ocean. Tech. 2008, 25, 519-533. [CrossRef]

20. Winker, D.M.; Hunt, W.H.; Hostetler, C.A. Status and Performance of the CALIOP Lidar. In Proceedings of the SPIE 5575 Laser Radar Techniques for Atmospheric Sounding, Canary Islands, Spain, 4 November 2004.

21. Nayak, M.; Witkowski, M.; Vane, D.; Livermore, T.; Rokey, M.; Barthuli, M.; Gravseth, I.J.; Pieper, B.; Rodzinak, A.; Silva, S.; et al. CloudSat Anomaly Recovery and Operational Lessons Learned. In Proceedings of the 12th International Conference SpaceOps, Stockholm, Sweden, 11-15 June 2012.

22. Wilks, D.S. Statistical Methods in the Atmospheric Sciences, 2nd ed.; Elsevier: New York, NY, USA, 2006; pp. 260-269.

23. Menzel, W.P.; Frey, R.; Baum, B. Cloud Top Properties and Cloud Phase Algorithm Theoretical Basis Document; MODIS Algorithm Theoretical Basis Document No. ATBD-MOD-06, Version 8; NASA: Greenbelt, MD, USA, 2010. Available online: http://modis-atmos.gsfc.nasa.gov/_docs/CTP_ATBD_oct10.pdf (accessed on 23 March 2016).

24. Hewison, T.; Muller, J. Ice Contamination of Meteosat/SEVIRI Implied by Inter-Calibration against Metop/IASI. IEEE Trans. Geosci. Remote Sens. 2013, 51, 1182-1186. [CrossRef]

25. Hartmann, D.L.; Ockert-Bell, M.E.; Michelsen, M.L. The effect of cloud type on the earth's energy balance: Global analysis. J. Clim. Appl. Meteorol. 1992, 8, 1-16. [CrossRef]

26. Wang, P.H.; Minnis, P.; McCormick, M.P.; Kent, G.S.; Skeens, K.M. A 6-year climatology of cloud occurrence frequency from Stratospheric Aerosol and Gas Experiment II observations (1985-1990). J. Geophys. Res. 1996, 101, 29407-29429. [CrossRef]

27. Wylie, D.P.; Menzel, W.P. Two years of cloud cover statistics using VAS. J. Clim. 1989, 2, 380-392. [CrossRef]

28. Wylie, D.P.; Menzel, W.P.; Woolf, H.M.; Strabala, K.I. Four years of global cirrus cloud statistics using HIRS. J. Clim. 1994, 7, 1972-1986. [CrossRef]

29. Wylie, D.P.; Menzel, W.P. Eight years of High cloud statistics using HIRS. J. Clim. 1999, 12, 170-184. [CrossRef]

30. Weisz, E.; Li, J.; Menzel, W.P.; Heidinger, A.K.; Kahn, B.H.; Liu, C.Y. Comparison of AIRS, MODIS, CloudSat and CALIPSO cloud top height retrievals. Geophys. Res. Lett. 2007, 34, L17811. [CrossRef]

31. Holz, R.; Ackerman, S.; Nagel, F.; Frey, R.; Dutcher, S.; Kuehn, R.; Vaughan, M.; Baum, B. Global Moderate Resolution Imaging Spectroradiometer (MODIS) cloud detection and height evaluation using CALIOP. J. Geophys. Res. 2008, 113, D00A19. [CrossRef]

32. Pavolonis, M.J.; Heidinger, A.K. Daytime cloud overlap detection from AVHRR and VIIRS. J. Appl. Meteorol. 2004, 43, 762-778. [CrossRef]

33. Minnis, P.; Huang, J.; Lin, B.; Yi, Y.; Arduini, R.F.; Fan, T.F.; Ayers, J.K.; Mace, G.G. Ice cloud properties in ice-over-water cloud systems using Tropical Rainfall Measuring Mission (TRMM) visible and infrared scanner and TRMM microwave Imager data. J. Geophys. Res. 2007, 112, D06206. [CrossRef]

34. Watts, P.; Bennartz, R.; Fell, F. Retrieval of two-layer cloud properties from multispectral observations using optimal estimation. J. Geophys. Res. 2011, 116, D16203. [CrossRef]

(C) 2016 by the authors; licensee MDPI, Basel, Switzerland. This article is an open access article distributed under the terms and conditions of the Creative Commons Attribution (CC-BY) license (http:/ / creativecommons.org/licenses/by/4.0/). 